\title{
ICU Recall 3rd Edition
}

\author{
Nelson L. Thaemert, Charles E. Hobson, Curtis G. Tribble (eds). Recall series \\ editor: Lorne H. Blackbourne. Wolters Kluwer Health/Lippincott Williams \\ and Wilkins, Baltimore, MD, and Philadelphia, PA, 604 pp, \\ ISBN 13: 978-0-7817-7653-0; ISBN 10: 0-7817-7653-8
}

John Tucker, MD

Published online: 9 May 2009

(C) Canadian Anesthesiologists' Society 2009

ICU Recall 3rd Edition is part of an extensive and popular series of handbooks covering basic science and clinical topics. There are no less than 18 titles to date. This edition is organized into four sections: Overview, Organ Processes, Systemic Processes, and Particular ICU Populations. A question and answer format is used, with the questions being of equal importance as the answers.

The editors give credit to students and residents, as well as to ICU experts, in the writing of this book, which is a practical guide for a wide range of readers. This clear concise and informative handbook for students and residents includes many lists, grading and classification tables, formulas, mnemonics and useful diagrams. It is an excellent pocketbook manual for quick review in the clinical environment, as well as a useful and easy-to-read reference book for clinical ICU topics.

Although it is a helpful pocketbook for ICU practitioners to use for reference and review, perhaps it is most valuable as a guidebook to enhance clinical teaching of residents and students in the ICU. Often the best bedside teaching is in the form of asking the right questions, and ICU Recall is an excellent source for accomplishing that end.

The only criticism of ICU Recall is the minimal amount of attention it devotes to various newer ICU technologies and advances in ICU evidence-based care. For example, topics such as newer ventilation methods, dynamic monitoring for fluid optimization, early goal-directed therapy in septic shock, early renal replacement therapy, glucose control, and restrictive transfusion practices are short on details. However, perhaps these topics are best learned from a review of the current literature in journals and at meetings and conferences, rather than from reading a clinical ICU handbook.

Having read ICU Recall, it is easy to understand why the Recall series of pocketbooks has become extensive and popular. The series is highly recommended for students, residents, and ICU specialists.
J. Tucker, MD ( $\varangle)$

Memorial University, St. John's, Newfoundland, Canada

e-mail: datucker@nl.rogers.com 